\title{
A STUDY ON WORK LIFE BALANCE AMONG THE TEACHING PROFESSIONALS OF ARTS AND COLLEGES IN TUTICORIN DISTRICT
}

\author{
C. Muthulakshmi \\ Department of PG and Research Department of Commerce, G. Venkataswamy Naidu College, India
}

\begin{abstract}
The study was conducted among the teaching professionals of arts and science colleges in Tuticorin District. This study is an attempt to explore the tough challenges faced by the respondents in maintaining a balance between their personal and professional life. The study is based on primary data. A sample of 200 respondents was selected by random sampling method. The various factors affecting the work-life balance of respondents have been examined in this study. The present study addresses the objective of understanding the socio economic profile of respondents, their opinion about their career, work life balance, factors influencing them towards their work life balance and imbalances and outcome of work life balance and imbalances. The attitude of respondents about the influence of work life balance on life satisfaction, impact of work life balance on their personal, social, family, environmental and psychological outlook have been made. The study also intends to measure the attitude of managing work life balance by the respondents. In order to address the objectives, the relevant hypotheses have been framed as the focus of relational basis namely testing the existence of significance difference among the working women about their work life balance issues, impact of work life balance, outcome and way of managing the work life balance related aspects through the relevant statistical tools like Chi-Square test, ANOVA, Correlation, Garrett Ranking Technique and factor analysis.
\end{abstract}

\section{Keywords:}

Work Life Balance, Teaching Professionals, Professional Life, Personal Life

\section{INTRODUCTION}

In organizations and on the home front, the challenge of work or life balance is rising to the top of many employers and employees consciousness. In today's fast-paced society, human resource professionals seek options to positively impact the bottom line of their companies, improve employee morale, retain employees with valuable company knowledge, and keep pace with workplace trends. In society filled with conflicting responsibilities and commitments work or life balance has become a predominant issue in the workplace.

Today, in the fast running phase of life, people really find it difficult to manage a balance between the pressures of work place and the duties of a home-maker, be it a male or female. Their life hops at either end of a see-saw and often ends up in a juggling life. This contemporary managerial issue has become a challenging factor of not only the young corporate who had just started their family life but also the young and middle-aged parents who needs to provide constant attention to their children who are fast-growing students or young adults. Adapting to a strategy where an emotional intelligence becomes the lead factor would help achieve equilibrium of Work-Life Management.
Work-life balance is an issue not just for individuals, but for employers, the market, the state and society as a whole. The future workforce and consumer market is dependent on women bearing, and parents raising children. The move from a single male breadwinner family model to one where both parents participate in paid employment has made it increasingly difficult to raise children while the workplace continues to be modeled on male breadwinner workers.

"Work-family balance" evolved into "work-life balance" partly in response to workers without family responsibilities who felt that employees with children were getting benefits that they were not. The term "life" applies to any non-paid activities or commitments. While the term does not generally include "unpaid work" when referring to work, it could be extended to cover that.

In very past years, organizations looked at "work" and "life" as independent domains. Employees were expected to place the organizations' interests ahead of their own. In the past, organizations reacted that, what happens to employees outside the office is their own business; what they do in the office is their business." With changing time, attitudes have changed. Organizations and managers today have come to accept the impact that work-life has on personal life and vice-versa. Recent years have seen a growing number of organizations operate under the assumption that personal life and work life are complementary to each other and not competing priorities. It helps employees balance their work lives with their personal life and leads to positive outcomes for the employee and the organization.

Therefore, a growing number of organizations have begun to adopt "work-life (family) programs" or "family-friendly practices". Work-life balance is the term used to describe those practices at work place that acknowledge and aim to support the needs of employees in achieving a balance between the demands of their family life and work lives.

Work Life Balance can be defined as the perfect integration between work and life both not interfering with each other. In the current business world, people and organizations are working round the clock to meet the ever-growing demands. A slight delay in meeting the schedules or expectations is considered to be an organizational failure. To avoid delays and failures, employees are working hard and giving their heart and soul to achieve worklife balance which is creating an enormous pressure on them and hence they are forced to finish their jobs irrespective of time limit. The most-often used phrase among the employees is that they don't have time or they have a hectic schedule. A day of 24 hours is no longer enough to perform work-related and personal-related duties or responsibilities. The problem seems simple but difficult to solve and handle. Employees who have to play another role of daughter or son or spouse or parents are not able to manage their roles. Observing the day-to-day lives of many employees, two main issues to be addressed to achieve work-life balance are time 
and stress. Managing these two variables is the secret of a perfect work-life balance. The HR department of the organization should assist the employee to maintain a work-life balance. The HR manager must carefully identify the issue and find a solution with the co-operation of the employer. Organization must include providing work-life balance as an HR policy.

Work-life balance issues appear to affect some groups of people more than others - those working long hours, those whose work spills over into the home as a result of modern technology, those in non-standard employment such as shift work, those on low incomes, those trying to juggle parenting and paid work, and those with cultural obligations beyond the family and paid work.

\subsection{STATEMENT OF THE PROBLEM}

Now a days, employers expect more from staff, and the employees are increasingly putting additional pressure on them to achieve greater results. Today's workers have many competing responsibilities such as work, children, housework, volunteering, spouse and elderly parent care and this places stress on individuals, families and the communities in which they reside. Work-life balance is about creating and maintaining supportive and healthy work environments, which will enable employees to have balance between work and personal responsibilities and thus strengthen employee loyalty and productivity. Maintaining work life balance is not only important for their personal health and relationships, but it can also improve the efficiency of their work performance. In today's fast paced business world, the ability to achieve work life balance is becoming more and more difficult. Hence, teaching professionals needs a very much consideration in maintaining their work life balance. Hence, the researcher has made an attempt to conduct the study on Work life Balance of teaching professionals of Arts and Science Colleges in Thoothukudi district.

\subsection{SCOPE OF THE STUDY}

The current study has covered the teaching professionals of arts and science colleges of five taluks namely Thoothukudi, Kovilpatti, Santhankulam, Srivaikundam, and Tiruchendur in Thoothukudi district. The study has emphasized the analysis of demographic profile of the respondents, and relationship between demographic variables and the level of attitude towards teaching profession. The analysis of finding out the significant difference between gender of the respondents and level of attitude towards the strategy to improve Work life Balance at work place, marital status of the respondents and level of attitude towards the strategy to improve Work life Balance at home, and the level of job satisfaction of the respondents and the level of attitude towards Work life Balance has also been covered in this study. The study has primarily focused on the factors determining the level of attitude of the respondents towards teaching profession, and the factors influencing the level of attitude of the respondents towards Work life balance.

\section{REVIEW OF LITERATURE}

Senthil kumar et al. [1] focused on teaching professionals with the objectives of finding the relationship between the demographical variables (such as marital status and partner employment status) and the level of stress in balancing work and life. The study found that $109(55.3 \%)$ respondents belonging to middle age category and their level of stress in balancing work and life, High level of stress perceived is the highest $(63.5 \%)$ among the female respondents. Majority (90\%) of the respondents were not satisfied with their work-life balance due to their work load. The study concluded that in this modern world, the role of teaching professionals are ever changing and evolving and the new teaching learning environment puts heavy pressure on teaching professionals. This work pressure will have an impact on their personal life and lead to imbalance in their work and life. Hence, teaching professionals' work life balance is the most important aspect in the success and development of educational institutions. It is vital for any institution to provide facilities to their staff members to get relieved from stress for balancing their work and personal life. The further research may determine the suitable work-life balancing programs for teaching faculty members in higher learning institutions in India.

Lakshmi and Sujatha [2] analyzed the Rotated component matrix it is clear that first component has four factors with heavy loading, viz. marital status, working hours, requirement of flexibility, additional working hours and over time. It is very clear that it is the volume and length of working hours which distort the work life balance. The test result indicated statistically significant relationship between marital status and overtime work. It was also found that among these 30 married women 14 preferred to work in the weekends while the remaining were prepared to work in the morning or evening of every working day. One more finding is that these $37 \%$ of the married women mainly work for financial reasons. The study concluded that above discussion, it is reasonable to modern organizations, especially educational institutions should address the Work Life Balance related issues among their staff, specifically women and take a holistic approach to design and implement policies to support the teaching staff to manage their work life balance which would add to the performance of these staff members.

Subha [3] concluded that modern organizations, especially educational institutions, should address the Work Life Balance related issues among their staff, specifically women and take a holistic approach to design and implement policies to support the teaching staff to manage their work or life balance which would add to the performance of these staff members. Achieving a good balance between work and family commitments is a growing concern for contemporary employees and organizations.

Mohammad et al. [4] concluded that both family and job of female teachers of Bangladesh are being affected due to work-life balance situation. women in the work place can be blessings only when both family as well as organization will receive proper service from them and they will be able to contribute to both family as well as organization only when the origination will ensure flexible working hours (roistered days off and family friendly starting and finishing times), transport facility, residential facility, child care center, flexible work arrangements or job sharing, reduced working hours \& workload and child schooling for the female teachers.

Venkataramanan and Abirami [5] suggested that understanding of stress in management teaching professionals may not only form the basis of stress analysis but may also be useful in rationalizing stress behavior and formulating coping strategies for the entire teaching professionals. Based on this 
information the working conditions may be improved. Information generated from this additional study of stress has the potential to increase job satisfaction and to reduce the turnover rate for experienced as well as the new teaching professionals. The study concluded that may be done by improving upon the pay packets and fringe benefits so that faculty members may feel pride in their job and perform to the best of their capacity, thereby increasing job satisfaction and reducing stress. The findings of the study can justify its utility since knowing the management faculty members precisely and reaching out to them in the effective way, is the key to minimize stress. The study can also direct employers of management institutes to evolve flexible work strategies and provide better working conditions which will help in overcoming stress in faculty members to some extent.

Ashok and Ebria [6] suggested that more time to be spent with the family members and try to know what they need. This is a major aspect in work-life balance. Missing the quality time with family due to work pressure leads to dispute in family. Main concern shall be given to family by proper scheduling of work. Scheduling the work and performing it according to time improves the quality of work-life balance. A little break or relaxation during work can do wonders and improves the performance. The study concluded that acts as a cycle where work pressure affects the family life; once the family life gets affected then it leads to decline in quality of work. Avoiding official work in personnel time and scheduling appropriate time for work and personnel life can lead to a healthy work-life condition.

Ratha [7] concluded that no debate on the fact that work life balance is essential and important for a stress free and fulfilling life, especially for a woman and justify its utility since knowing the faculty members precisely and reaching out to them in the effective way, is the key to minimize stress. The study can also direct employers of institution to evolve flexible work strategies and provide better working conditions which will help in overcoming stress in faculty members to some extent.

Adeeba and Feza [8] concluded that since the respondents are almost of the same age, there are similarities in their perceptions. So gender was not found to be a significant differentiating factor. No significant difference was observed among teachers on the basis of marital status, occupation of spouse, number of dependents and age on the dimension of Work Interference with Personal Life, Personal Life Interference with Work and Work Personal Life Enhancement. Since the respondents are from school as well as university, there are differences in their perceptions. Although they are teaching in the same university, they share differences in physical evidence and type of students and work hours, differences in workload, training requirements and nature of course that they are teaching. Teachers in professional courses usually experience more work-life pressures. It may therefore give insight to university authorities regarding the problems that teachers usually face in their lives. Interaction between teacher and higher authorities should be enhanced so that teachers can share their problems. Interaction between authorities and teachers should be enhanced to understand WLB issues confronting them. Balance should be established between workload distribution, leisure time and extra-curricular activities so as to engender academic excellence.

Dhanya and Kinslin [9] concluded that best practices for WLB includes Flexi time, Work commuting, Five days' work per week,
Planned vacations, leave facilities including maternity leave, employee welfare schemes and talent development initiatives. Some innovative ideas need to evolve in this context for reducing work life imbalance.

\section{OBJECTIVES OF THE STUDY}

- To study the demographic profile of the respondents.

- To analyze the relationship between demographic variables and the level of attitude towards Work life Balance of teaching professionals.

- To analyze the relationship between gender of the respondents and level of attitude towards the strategy to improve Work life Balance at work place.

- To analyze the relationship between marital status of the respondents and level of attitude towards the strategy to improve Work life Balance at home.

- To compare and find out relationship between the level of job satisfaction of the respondents and the level of attitude towards Work life Balance.

- To identify the factors determining the perception of the respondents towards teaching profession.

- To identify the factors influencing Work life Balance.

\section{HYPOTHESIS OF THE STUDY}

- $\mathrm{H}_{01}$ : There is no significant relationship between age of the respondents and the level of attitude towards work life balance of teaching professionals.

- $\mathrm{H}_{02}$ : There is no significant relationship between gender of the respondents and the level of attitude towards work life balance of teaching professionals.

- $\mathrm{H}_{03}$ : There is no significant relationship between the years of working experience of the respondents and the level of attitude towards work life balance of teaching professionals.

- $\mathrm{H}_{04}$ : There is no significant difference between gender of the respondents and level of attitude towards the strategy to improve work life balance at work place.

- $\mathrm{H}_{05}$ : There is no significant difference between marital status of the respondents and level of attitude towards the strategy to improve work life balance at home.

- $\mathrm{H}_{06}$ : There is no significant difference between the level of job satisfaction of the respondents and the level of attitude towards work life balance.

\section{RESEARCH METHODOLOGY}

The data required for the study were collected from both the primary sources and secondary sources. The primary data has been collected directly from teaching professionals by using the pre-defined well-structured questionnaire. Totally 150 samples were collected from Five Taluks in Thoothukudi district viz., Thoothukudi, Kovilpatti, Santhankulam, Srivaikundam, and Tiruchendur by adopting stratified random sampling technique. 30 respondents were selected from each Taluk of Thoothukudi District. 
The various statistical tools applied to analyse the primary data are Percentage analysis, Chi-Square test, One-way ANOVA and Factor analysis. In order to interpret the data to arrive at findings from the study, for effective analysis and easy understanding, the data were tabulated. The secondary data were collected from the published journals, books, magazines and websites.

\section{FINDINGS}

The overall findings of the study are classified under four categories:

- Percentage Analysis

- Chi-Square Test Analysis

- One-way ANOVA Analysis

- Factor Analysis

\subsection{PERCENTAGE ANALYSIS}

- Majority (62\%) of the respondents are females.

- Majority (38\%) of the respondents are in the age group of 31 to 35 years.

- Majority of the respondents (70\%) are married.

- Majority (56\%) of the respondents have completed M.Phil course.

- Majority (76\%) of the respondents are Hindus.

- $(50 \%)$ of the respondents belong to the joint family and another $(50 \%)$ of them belong to the nuclear family.

- Majority (60\%) of the respondents' are have 3 to 4 members in the family.

- Majority (54\%) of the respondents are staying in own house.

- Majority (38\%) of the respondents have 1 child.

- Majority $(50 \%)$ of the respondents are take care for their children from relatives.

- Majority (52\%) of the respondents' spouse are employed.

- Majority (46.15\%) of the respondents' spouse are employed in private enterprises.

- Majority $(84 \%)$ of the respondents are coming under the category of Assistant Professor Grade.

- Majority (86\%) of the respondents are appointed by consolidated basis.

- Majority $(90 \%)$ of the respondents are working in SelfFinancing Colleges.

- All $(100 \%)$ the respondents are working in Co-Education colleges.

- Majority $(96 \%)$ of the respondents are working in NonAutonomous colleges.

- Majority (48\%) of the respondents are having the teaching experience of below 3 years.

- Majority (90\%) of the respondents are earning a monthly salary of Less than Rs. 10, 000.

- Majority (52\%) of the respondents are not satisfied with their salary.
- Maximum (94\%) respondents are received provident fund benefits.

- Majority (80\%) of the respondents are working for 6 days in a week.

- Majority (46\%) of the respondents are working for Less than 5 hours in a day.

- Majority (46\%) of the respondents are selecting the teaching profession for their self-interest.

- Majority (56\%) of the respondents feel that their job is knowledge updating.

- Majority (36\%) of the respondents their leave home for work at Morning 8.30AM.

- Majority (34\%) of the respondents reach home at Evening 5 PM and another $34 \%$ of the respondents reach home at above 5.30PM.

- Majority (42\%) of the respondents are taken leave for their personal illness.

\subsection{CHI-SQUARE TEST ANALYSIS}

The calculated value of Chi square test is 9.467 which is in significant at $5 \%$ level as its $p$ value is more than 0.304 . Thus, the null hypothesis is accepted. Hence, it is proved that there is no significant relationship between age of the respondents and the level of attitude towards work life balance.

The calculated value of Chi square test is 1.039 which is insignificant at $5 \%$ level as its $p$ value is more than 0.595 . Thus, the null hypothesis is accepted. Hence, it is proved that there is no significant relationship between gender of the respondents and the level of attitude towards work life balance.

The calculated value of Chi Square test is 22.105, which is significant at $5 \%$ level as its $p$ value is less than 0.01 . Thus, the null hypothesis is rejected. Hence, it is proved that there is a significant relationship between the years of working experience of the respondents and the level of attitude towards work life balance.

\subsection{ONE-WAY ANOVA ANALYSIS}

One-way ANOVA has been applied to find out the significant difference between gender of the respondents and level of attitude towards the strategy to improve work life balance at work place. The calculated values are $F=5.340$ and $p=0.022$. As $P>0.022$, it is found to be significant at $5 \%$ level of significance. Hence, the null hypothesis is rejected and it is concluded that there is a significant difference between gender of the respondents and level of attitude towards the strategy to improve work life balance at work place.

One-way ANOVA has been applied to find out the significant difference between marital status of the respondents and level of attitude towards the strategy to improve work life balance at home. The calculated values are $F=0.142$ and $p<0.707$. As $P<$ 0.707 , it is not found to be significant at $5 \%$ level of significance. Hence, the null hypothesis is accepted and it is concluded that there is no significant difference between marital status of the respondents and level of attitude towards the strategy to improve work life balance at home. 
One-way ANOVA has been applied to find out the significant difference between the level of job satisfaction of the respondents and the level of attitude towards work life balance. The calculated values are $F=4.114$ and $p>0.018$. As $P>0.018$, it is found to be significant at $5 \%$ level of significance. Hence, the null hypothesis is rejected and it is concluded that there is a significant difference between the level of job satisfaction of the respondents and the level of attitude towards Work life Balance.

\subsection{FACTOR ANALYSIS}

Factor analysis has been applied to analyse the factors influencing the Work Life Balance among the teaching professionals of arts and science colleges in Tuticorin district. All the 57 statements describing the agreement among the work life balance are grouped into ten factors named as Risk Involved and Reward (0.743), Attitude (0.790), Professional Knowledge and Skills (0.767), Opportunities (0.830), Co-operation (0.798), Stress Level (0.865), Nature of Job (0.715), Mind-set (0.714), People (0.788) and Feelings (0.754).

Factor analysis has been applied to analyze the factors influencing the Work Life Balance among the teaching professionals of arts and science colleges in Tuticorin district. All the 32 statements describing the agreement among the work life balance are grouped into ten factors named as welfare measure (0.872), Promotion and career advancement (0.803), Monetary package (0.844), Family support (0.863), Social Status (0.705), Co-worker Support (0.829), Sensitivity (0.879), Family functions Celebrations (0.745), Bonus Payments (0.817) and Comfortable future earnings (0.691).

\section{SUGGESTIONS}

The following are the suggestions offered to improve the Work life balance.

\subsection{SUGGESTIONS TO THE MANAGEMENT}

- The management may arrange seminars and awareness programmes about stress and overburden, work-life balance and individual energy management to make better choices about balancing their energies across their work and life.

- Consider providing training in relaxation methods, such as Yoga and meditation. These practices help strengthen the body and lower stress.

- Institutions need to create counselling services in their respective organizations through counsellors who can help teaching staff members in balancing their mental and physical rhythm.

- The management shall facilitate work life balance with many schemes that can attract teaching staff members and satisfy their needs.

- Free health checkups, health insurance \& exercise facilities are the Initiatives which are the critical influencing factors for teaching staff members used as good retention tools.

- The management should inculcate the belongingness among teaching staff members and arrange stress reducing activities like get together, cultural or recreational programmes as and when required.
- The management may provide adequate accommodation facility inside the campus to reduce the travel time and tension of the teaching staff members.

\subsection{SUGgESTIONS TO THE TEACHING STAFF MEMBERS}

- The teaching staff members have to plan, prioritize and schedule their work and life obligations in order to improve their work life balance.

- They shall think about what they want out of work and out of life.

- They shall agree that they will delegate.

- They may plan ahead for continuous professional development (CPD) and studying and make sure they stick to the plan.

- They may involve in such activity that will help them relieve the stresses that are part of the job like a walk in the evening, alternative therapies or going to concerts.

- They may look at the NHS Management website, www.nhsmanagement.org, which has a whole section on managing work-related stress and links to other sites where they can find a range of good advice.

- They shall talk to their family, friends and colleagues about what they are doing and why it is necessary in order to get their buy-in and support.

\section{CONCLUSION}

The growing diversity of family structures represented in the workforce, including dual-earner couples, single parents, blended families, teaching staff members with elder care responsibilities and the increasing number or people choosing to live alone, has heightened the relevance of balancing work and life roles for a substantial segment of employed men and women. These societal developments have greatly increased the complexities of the interface between work and life roles especially in case of educational institutions.

Institutions should consider child supervision to be better regulated than teaching staff members do. At the same time, teaching staff members 'expectations of balance in this area are high. It should therefore be pointed out to management that more attention could be devoted to this area. Apart from this, flexible working time is also an area which requires particular attention from management. The incorporation of Work-Life Balance strategies into annual planning of educational institutions can, in fact, have positive impact on employee's well-being.

Therefore, it is equally important for teaching staff members to express their expectations and needs, since otherwise they cannot expect management or the institutions to resolve matters for them on their own initiative.

\section{REFERENCES}

[1] K.G. Senthilkumar, S. Chandra kumara Mangalam and L. Manivannan, "An Empirical Study on Teaching Professionals Work-Life Balance in Higher Learning Institutions with Special Reference to Namakkal District, 
Tamilnadu", Bonfring International Journal of Industrial Engineering and Management Science, Vol. 2, No. 3, pp. 14, 2012.

[2] K. Santhana Lakshmi and S. Gopinath Sujatha, "Work Life Balance Of Women Employees-with Reference to Teaching Faculties", International Monthly Refereed Journal of Research in Management and Technology, Vol. 2, pp. 5362, 2013.

[3] T. Subha, "A Study on Work Life Balance Among Women Faculties Working in Arts and Science Colleges with Special Reference to Coimbatore City", Paripex-Indian Journal of Research, Vol. 2, No. 12, pp. 160-163, 2013.

[4] M.R. Uddin, A.M.A. Mamun, Nazamuland Hoque and M.S. Uddin,"Work-Life Balance: A Study on Female Teachers of Private Education Institutions of Bangladesh", European Journal of Business and Management, Vol. 5, No. 13, pp. 10-17, 2013.

[5] M. Venkataramanan and N. Abirami, "A Study on WorkLife Balance of Women Teachers in Arts and Science
Colleges in Tamil Nadu", Indian Journal of Applied Research, Vol. 3, No. 11, pp. 1-6, 2013.

[6] Ashok. P. Alexander and Khakhlari Ebria, "Work-Life Balance: A Study among the Teaching Staffs of Bengtol College of Chirang District, Assam", Indian Journal of Applied Research, Vol. 5, No. 10, pp. 21-25, 2015.

[7] R. Anu, "A Study of Work Life Balance of Female Teaching Professionals in Coimbatore", Abhinav National Monthly Refereed Journal of Research in Commerce and Management, Vol. 4, No. 4, pp. 112-116, 2015.

[8] A. Irfan and F.T. Azmi, "Work Life Balance among Teachers: An Empirical Study", IOSR Journal of Business and Management, Vol. 17, No. 2, pp. 1-11, 2015.

[9] J.S. Dhanya and D. Kinslin, "A Study on Work Life Balance of Teachers in Engineering Colleges in Kerala", Journal of Chemical and Pharmaceutical Sciences, Vol. 9, No. 4, pp. 1-7, 2016. 